ISSN: $1679-3013$

D.O.I.: 10.5914/to.2014.0111

\title{
PICO, NANO E MICROPLÂNCTON EM QUATRO GAMBOAS DO MUNICÍPIO DE PONTAL DO PARANÁ, PARANÁ, BRASIL
}

Hedda Elisabeth KOLM ${ }^{1 *}$

Adriana SIQUEIRA.

Recebido em: 22/02/2013

Aceito em: $20 / 10 / 2014$

\section{RESUMO}

Ambientes costeiros como baías, estuários e gamboas são importantes por serem regiões de alta produtividade e influenciadas por atividades antrópicas. Neste estudo foram avaliadas o pico, nano e microplâncton auto e heterotrófico em gamboas do município de Pontal do Paraná. Foram realizadas coletas trimestrais, entre abril de 2003 e abril de 2004, de águas superficiais de três estações de quatro gamboas (Perequê, Penedo, Barranco e Olho d'Água) durante as baixamares de sizígia. Quantidades maiores de organismos protozooplanctônicos foram diretamente relacionadas com o fitoplâncton nas estações externas de todas as gamboas, destacando-se as da Gamboa Perequê. Houve uma correlação direta entre o protozooplâncton e o picoplâncton heterotrófico no outono e primavera de 2003 e verão de 2004 e inversa no inverno de 2003 e outono de 2004. Entre o protozooplâncton e o nanoplâncton heterotrófico a correlação foi direta no inverno, verão e outono de 2004 e inversa no outono de 2003. Na primavera, a quantidade de nanoplâncton heterotrófico não apresentou relação quantitativa com o protozooplâncton. Estes resultados indicam que, na região estudada, a maior salinidade, maior transparência da água e principalmente maior quantidade de fitoplâncton parecem ser mais importantes para o protozooplâncton que uma possível quantidade de pico- e nanoplâncton heterotrófico.

Palavras chave: Gamboas, autotrófico, heterotrófico, Pontal do Paraná.

\section{ABSTRACT}

Coastal environments as bays, estuaries and tidal creeks are important because of its high productivity and influence of anthropic activities. In this study auto and heterotrophic piko- nano and microplankton were evaluated in tidal creeks of the municipal district of Pontal do Paraná. Quarterly sampling, between April 2003 and April 2004, were accomplished from surface waters of three stations of four tidal creeks (Perequê, Penedo, Barranco and Olho d'Água) during syzygy low tides. Larger amounts of protozooplanktonic organisms were directly related with fytoplankton in the external stations of all the tidal creeks, particularly of Gamboa Perequê. There was a direct correlation between the protozoo- plankton and heterotrophic pikoplankton in the autumn and spring of 2003 and summer 2004 and inverse in winter of 2003 and autumn of 2004. Between protozooplankton and heterotrophic nanoplankton the correlation was direct in the winter, summer and autumn of 2004 and inverse in autumn of 2003. In spring, the amount of heterotrophic nanoplankton did not show quantitative relation with the protozooplankton. These results indicate that, in the studied area, the largest salinity, larger water transparency and mainly larger amount of phytoplankton seem to be more important for the protozooplankton than a possible amount of heterotrophic piko - and nanoplankton.

Key words: Tidal creeks, autotrophic, heterotrophic, Pontal do Paraná.

\section{INTRODUÇÂO}

O plâncton é constituído por organismos pelágicos cujo poder de deslocamento é insuficiente para vencer a dinâmica das massas d'água. Segundo Valiela (1995), a comunidade planctônica apresenta um caráter muito dinâmico, com elevadas taxas de reprodução e perda, respondendo rapidamente às alterações físicas e químicas do meio aquático, estabelecendo

${ }^{1}$ Centro de Estudos do Mar da Universidade Federal do Paraná. Caixa Postal 61. 83.255-976 Pontal 
KOLM, H. E.; SIQUEIRA, A.pico, nano e microplâncton em quatro gamboas do município de Pontal do Paraná, Paraná, Brasil.

assim complexas relações intra e interespecíficas na competição e utilização do espaço e dos recursos.

As variações no regime meteorológico, nas características geomorfológicas regionais e nos impactos antropogênicos nas áreas costeiras, estabelecem, em conjunto, o regime hidrográfico particular de cada região e, conseqüentemente, as características taxonômicas e a dinâmica espacial e temporal das comunidades planctônicas (BRANDINI et al., 1997).

De acordo com a classificação dimensional de Sieburth; Smetacek; Lenz (1978), os componentes do plâncton podem ser divididos em várias categorias, destacando-se como constituintes do plâncton microbiano, o picoplâncton $(0,2-2,0 \mu \mathrm{m})$, o nanoplâncton $(2,0$ $20 \mu \mathrm{m})$ e o microplâncton $(20-200 \mu \mathrm{m})$.

Algumas cidades litorâneas do Brasil têm sua paisagem alterada devido ao grande crescimento em consequência da demanda turística, aumentos das atividades portuárias, extração e transporte de petróleo ao longo da costa, bem como devido à gradativa implantação de empreendimentos de aquicultura, aumentando os fatores de risco de poluição e eutrofização das águas (YONEDA, 2004). Tal fato tem implicações sobre as comunidades plactônicas, uma vez que a biodiversidade está relacionada com a poluição das águas, notadamente o aporte de matéria orgânica particulada e dissolvida, alterando o balanço dos nutrientes. Esse desequilíbrio pode levar a um processo de enriquecimento nutricional, a eutrofização, que pode favorecer o crescimento de espécies oportunistas em detrimento de outras mais sensíveis. Se o crescimento destas espécies oportunistas for explosivo, estará configurada a ocorrência de um "bloom" ou florescimento que, dependendo da espécie, pode constituir um fator de risco para a saúde pública humana (CRACKNELL et al., 2001; RELATÓRIO REVIZEE).

Considerando-se que a crescente urbanização nas proximidades das gamboas do litoral do Paraná tem causado evidentes mudanças na qualidade dos hábitats marinhos e que tais modificações não foram quantificadas até o momento, realizamos este estudo que procurou caracterizar a estrutura da alça microbiana na região. Desta forma, foi objetivo da presente pesquisa, estudar o picoplâncton em quatro gamboas do litoral do município de Pontal do Paraná, considerando-se os compartimentos auto e heterotrófico desta classe de tamanho de organismos.

\section{ÁREA ESTUDADA}

O Município de Pontal do Paraná (Figs. 1A e B) insere-se na planície costeira de Paranaguá, uma planície arenosa, de construção marinha, delimitada ao norte pelo Estuário de Paranaguá (Fig. 1A) e a oeste e sul pela Serra do Mar. As praias do município estendem-se desde o Canal do DNOS (canal artificial de drenagem), na desembocadura da Baía de Paranaguá, até o Balneário Monções (limite sul do município). Os principais balneários do município são Monções, Praia de Leste, Ipanema, Shangri-lá, Atami e Pontal do Sul. A população do município oscilou entre 20.920 (IBGE, 2012) habitantes residentes durante todo o ano em 2010 e 400 mil que compõem a população flutuante, principalmente durante as férias escolares (ANGULO et al., 1999).

Além do Rio Guaraguaçu, principal rio do município, são encontrados ainda os "rios" das Pedras, Embocuí, Emboguaçu, Maciel, Baguaçu, Penedo, Barranco, Perequê, Perequê Mirim e Olho D'água. Estas confluências de águas não são rios mas gamboas, ou seja, cursos de água de traçado meandrante, característicos de planícies litorâneas dos grandes complexos estuarinos (LANA et al., 1989) que não possuem nascentes e que, segundo Chrzanowski; Spurrier (1987), drenam o material em suspensão e demais produtos de processos físicos e biológicos de manguezais e marismas, exportando-os para sistemas aquáticos adjacentes. 
KOLM, H. E.; SIQUEIRA, A.pico, nano e microplâncton em quatro gamboas do município de Pontal do Paraná, Paraná, Brasil.
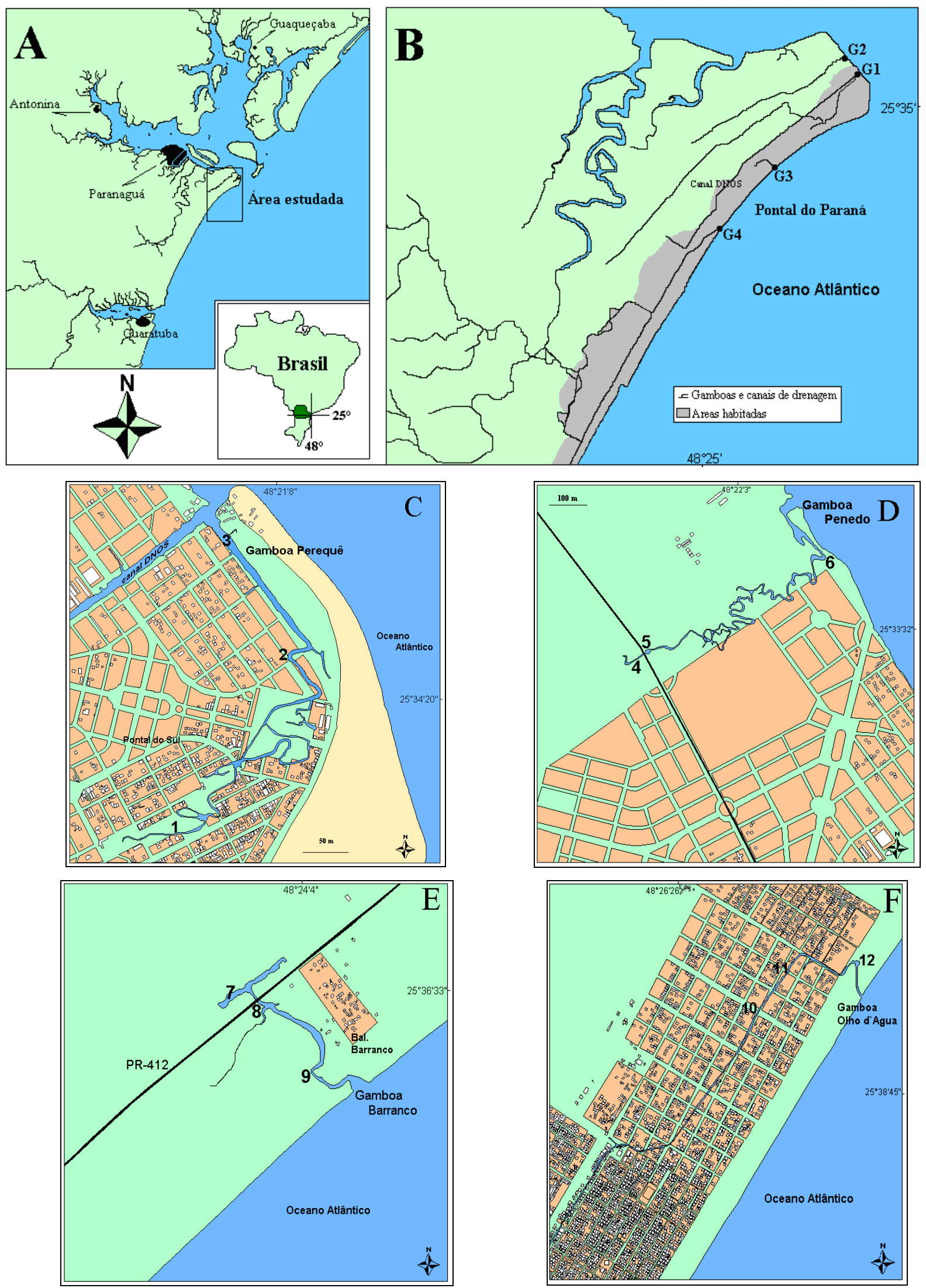

Figura 1 - A) Litoral do Paraná com localização da área estudada; B) Município de Pontal do Paraná com localização das gamboas onde G1 é a do Perequê, G2 do Penedo, G3 de Barrancos e G4 do Olho D'água; C) Gamboa do Perequê com localização dos 
KOLM, H. E.; SIQUEIRA, A.pico, nano e microplâncton em quatro gamboas do município de Pontal do Paraná, Paraná, Brasil.

pontos de coleta; D) Gamboa Penedo com localização dos pontos de coleta. E) Gamboa Barranco com localização dos pontos de coleta. F) Gamboa Olho d'Água com localização dos pontos de coleta.

Ao longo dos anos, grande parte das gamboas da região vem sofrendo, em maior ou menor grau, influências antrópicas. Atualmente o maior impacto refere-se à dragagem de seus leitos, interligação com canais de escoamento, recepção de águas pluviais e dos esgotos provenientes de povoados.

No presente trabalho foram estudadas quatro gamboas (Perequê, Penedo, Barranco e Olho d'Água) do Município de Pontal do Paraná. As gamboas Perequê e Olho d'Água estão localizadas em áreas urbanizadas (Figs. 1C e 1F). A do Penedo (Fig. 1D) é marginada por manguezais de pequeno porte próximos à sua desembocadura e vegetação arbórea de restinga no restante do seu percurso. Já próximo à desembocadura da Gamboa Barranco existe um pequeno povoado homônimo e nas regiões mais internas ela é marginada por vegetação de restinga (Fig. 1E). Detalhes sobre as gamboas estudadas podem ser encontrados em Siqueira et al., (2009).

\section{MATERIAL E MÉTODOS}

Durante as baixa-mares de sizígia foram realizadas, entre abril de 2003 a abril de 2004, coletas trimestrais de águas superficiais de três estações de cada gamboa (estações 1,2 e 3 Perequê; 4, 5 e 6 - Penedo; 7, 8 e 9 - Barranco e 10, 11 e 12 - Olho d'Água). Devido à distância entre uma gamboa e outra, e com o intuito de evitar a influência da maré, as coletas iniciadas no final da vazante foram feitas em dias consecutivos (Perequê e Penedo no primeiro dia e Barranco e Olho d'Água no segundo). Ainda para evitar a influência da maré, as coletas das gamboas Perequê e Barranco foram feitas do interior da gamboa para a desembocadura e na direção inversa nas gamboas Penedo e Olho d'Água. Para melhor compreensão, todos os dados foram plotados na mesma direção, i.e., das estações internas para as externas.

Os resultados dos parâmetros abióticos (precipitação, temperatura, salinidade, alcalinidade, dióxido de carbono, oxigênio dissolvido, fosfato, silicato, nitrato, nitrito, amônio e substâncias húmicas, material particulado em suspensão, substâncias húmicas assim como a clorofila, os coliformes totais e termotolerantes encontram-se registrados em Siqueira et al., (2009).

As amostras coletadas para a análise do pico- e nanoplâncton foram acondicionadas em recipientes plásticos de $100 \mathrm{~mL}$ envoltos em papel alumínio e fixadas imediatamente com uma solução de formol $2 \%$ neutralizado com borato de sódio.

A contagem total dos organismos pertencentes ao picoplâncton e nanoplâncton foi feita através de lâminas coradas pelo fluorocromo laranja de acridina e também com a fluorescência natural observada nos organismos autotróficos. Para a preparação das lâminas, as amostras foram pré-filtradas em rede de $25 \mu \mathrm{m}$. Em seguida, foram confeccionadas duas lâminas de cada amostra para cada fração, sendo filtradas, de acordo com a quantidade de organismos presentes em cada amostra, alíquotas de $0,5,1$ ou $2 \mathrm{~mL}$ para o picoplâncton total e de $15 \mathrm{~mL}$ para o picoplâncton autotrófico; $5 \mathrm{~mL}$ para o nanoplâncton total e $20 \mathrm{~mL}$ para o nanoplâncton autotrófico sobre membranas de celulose Millipore de 0,22 $\mu \mathrm{m}$ (para ambas as frações), cobertas por uma membrana pré-escurecida de policarbonato Nucleopore de 0,2 $\mu \mathrm{m}$ (picoplâncton) ou Osmonics de 1,0 $\mu \mathrm{m}$ (nanoplâncton). Todas as amostras foram filtradas com o auxílio de um compressor aspirador Diapump Fanem com pressão máxima de $10 \mathrm{~mm} \mathrm{Hg}$, para evitar a ruptura das células, e um suporte para membrana filtrante. Todo o procedimento foi realizado sob abrigo da luz, a fim de que a fluorescência natural fosse mantida.

As células de cada fração foram contadas, em aumento de 1000x, com auxílio de um microscópio Nikon, modelo Labophot equipado com epiflourescência, seguindo-se a metodologia descrita por Parsons; Maita; Lalli (1984). Para o picoplâncton foram contados os organismos de 12 campos óticos aleatórios e para o nanoplâncton 20 campos óticos aleatórios ou até alcançar um mínimo de 50 células. 
KOLM, H. E.; SIQUEIRA, A.pico, nano e microplâncton em quatro gamboas do município de Pontal do Paraná, Paraná, Brasil.

Para a avaliação quantitativa do microfitoplâncton e do protozooplâncton, foram coletados $200 \mathrm{~mL}$ de amostras, fixadas com solução de formol $2 \%$ neutralizado com borato de sódio e acondicionadas em potes plásticos. No momento da análise as amostras foram pré-filtradas em rede de $200 \mu \mathrm{m}$. As contagens foram efetuadas em microscópio invertido Zeiss, modelo ID 03, seguindo a metodologia descrita em Utermöhl (1958). A câmara de sedimentação utilizada foi a de $50 \mathrm{~mL}$. Em amostras com muito detrito ou muitos organismos utilizou-se a de $10 \mathrm{~mL}$. O procedimento da análise e a contagem seguiram a orientação de Hasle (1978). Cada amostra foi corada com uma solução estoque de Rosa de Bengala (1 mg de Rosa de Bengala $.100 \mathrm{~mL}^{-1}$ de água destilada), devidamente homogeneizada e deixada em repouso por um período de 24 horas. O aumento utilizado para contar as células foi o de $200 x$ e o número de transectos variou entre 1 a 6 ou até toda a câmara de sedimentação, de acordo com a quantidade de organismos e detritos. Tanto para o microplâncton quanto para o protozooplâncton, foram identificados apenas os grandes grupos taxonômicos com a utilização de bibliografia especializada.

As amostras do picoplâncton total, divididos em compartimentos autotrófico e heterotrófico, foram comparadas através da Análise de Variância (ANOVA) unifatorial, tendo como fator fixo as estações, gamboas e meses de coleta. Quando o resultado indicou diferença significativa, aplicou-se o teste a posteriori LSD para identificar as médias que variaram significantemente.

O método de ordenação MDS foi utilizado para identificar similaridades entre as densidades dos grupos taxonômicos do microplâncton das estações amostrais, distribuídas em diferentes gamboas durante os períodos de outono, inverno, primavera e verão. Quando necessário, empregou-se o teste de análise de similaridade ANOSIM (análise de similaridade). Uma vez agrupadas e detectadas as diferenças em um ou mais dos fatores (estações, gamboas e datas de coletas) foram identificadas as categorias (os grupos taxonômicos) responsáveis por esses resultados. Isto foi realizado utilizando-se a análise de percentagens de similaridade SIMPER, que serve para identificar os grupos taxonômicos responsáveis (mais comuns) pela similaridade dentro de cada grupo definido pelo MDS e apoiado pela ANOSIM e pela dissimilaridade entre esses grupos (mais discriminantes). Para efetuar as análises acima citadas, utilizou-se a média das densidades de cada grupo taxonômico.

Os procedimentos analíticos foram realizados através dos programas estatísticos Statistica, versão 6.0; Primer (Plymouth Routines in Multivariate Ecological Research), versão 5.1.2 e MVSP (Multi-Variate Statistical Package), versão 3.13.

\section{RESULTADOS}

A densidade da fração picoplânctonica total variou entre $22 \times 10^{4}$ céls. $\mathrm{mL}^{-1}$ (estação 7Gamboa Barranco/outono de 2003) a 491 x $10^{4}$ céls.mL ${ }^{-1}$ (estação 2 -Gamboa Perequê/primavera de 2003). Em relação às variações espacial e temporal, todos os valores de densidade foram significativamente baixos em todas as estações no outono de 2003 (Fig. 2). Valores baixos ainda foram observados em todas as estações da Gamboa Penedo no inverno de 2003 e na estação 5 da mesma gamboa ao longo dos demais períodos. No inverno de 2003 os valores foram significantemente maiores na estação externa do Olho d'Água (estação 12), na primavera de 2003 e no outono de 2004 na estação mediana (estação 2) da Gamboa Perequê e no verão de 2004 nas estações interna e mediana (estações 1 e 2) da mesma gamboa. 
KOLM, H. E.; SIQUEIRA, A.pico, nano e microplâncton em quatro gamboas do município de Pontal do Paraná, Paraná, Brasil.

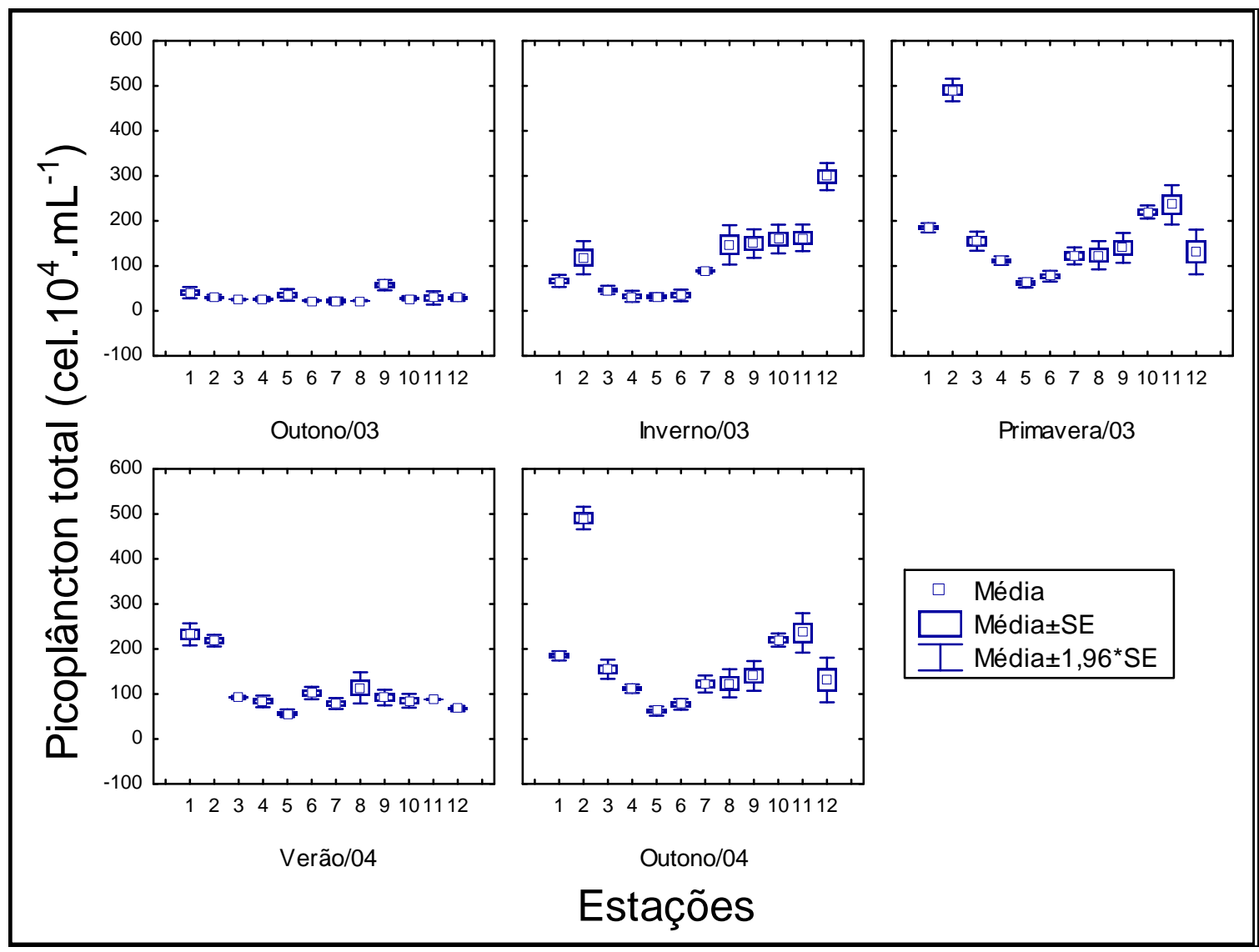

Figura 2 - Variação média da densidade do picoplâncton entre as estações nos períodos dos anos amostrados.

Quanto à contribuição dos componentes autotróficos e heterotróficos, observou-se que as bactérias heterotróficas dominaram em todas as estações. O menor valor de picoplâncton heterotrófico foi de $19 \times 10^{4}$ céls. $\mathrm{mL}^{-1}$, registrado na estação 7 (Gamboa Barranco) no outono de 2003, e o maior de $488 \times 10^{4}$ céls. $\mathrm{mL}^{-1}$ na estação 2 (Gamboa Perequê) na primavera do mesmo ano. O picoplâncton autotrófico variou de $0,9 \times 10^{4}$ céls. $\mathrm{mL}^{-1}$ registrado na estação 3 (Gamboa Perequê) no verão de 2004 a $4 \times 10^{4}$ céls. $\mathrm{mL}^{-1}$ na estação 7 (Gamboa Barranco) no inverno 2003.

O picoplâncton autotrófico apresentou pouca variabilidade ao longo das estações estudadas, entretanto ao longo do período seus valores foram significativamente menores no verão de 2004 (Fig. 3). A distribuição do picolâncton heterotrófico foi semelhante à do picoplâncton total (Fig. 4). 
KOLM, H. E.; SIQUEIRA, A. pico, nano e microplâncton em quatro gamboas do município de Pontal do Paraná, Paraná, Brasil.

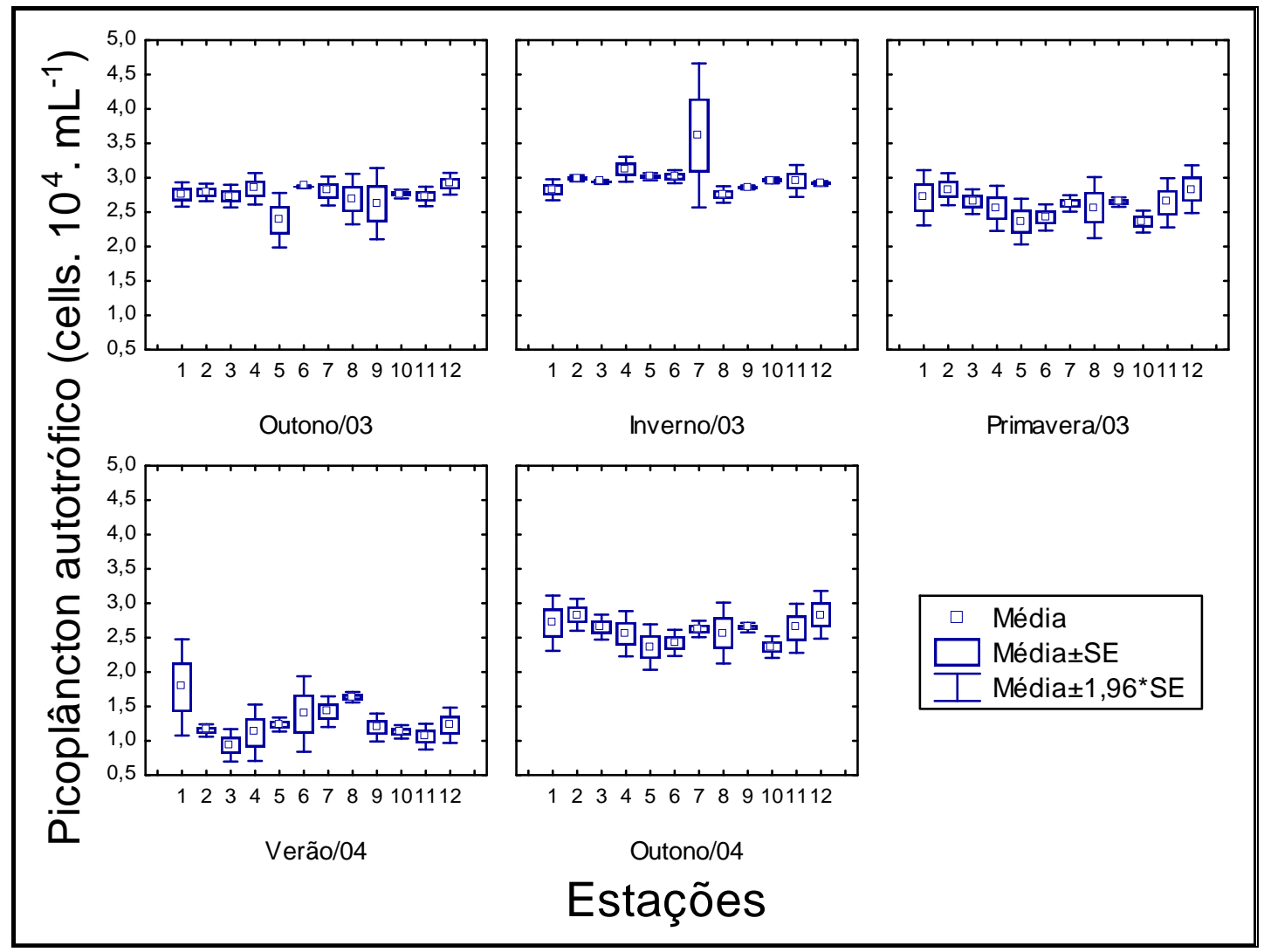

Figura 3 - Variação média da densidade do picoplâncton autotrófico entre as estações nos períodos dos anos amostrados.

A densidade celular do nanoplâncton foi heterogênea, com um mínimo de $4 \times 10^{4}$ céls. $\mathrm{mL}^{-1}$ registrado na estação 11 (Gamboa Olho d'Água) no outono de 2004 e um máximo de 22 x $10^{4}$ céls. $\mathrm{mL}^{-1}$ na estação 1 (Gamboa Perequê) durante o verão. Assim como o picoplâncton total, os menores valores foram observados no outono de 2003. No verão de 2004 seus valores foram extremamente altos na Gamboa Perequê e baixos nas demais gamboas. Nos demais períodos não puderam ser observados padrões de distribuição desta classe de micro-organismos (Fig. 5). 
KOLM, H. E.; SIQUEIRA, A.pico, nano e microplâncton em quatro gamboas do município de Pontal do Paraná, Paraná, Brasil.

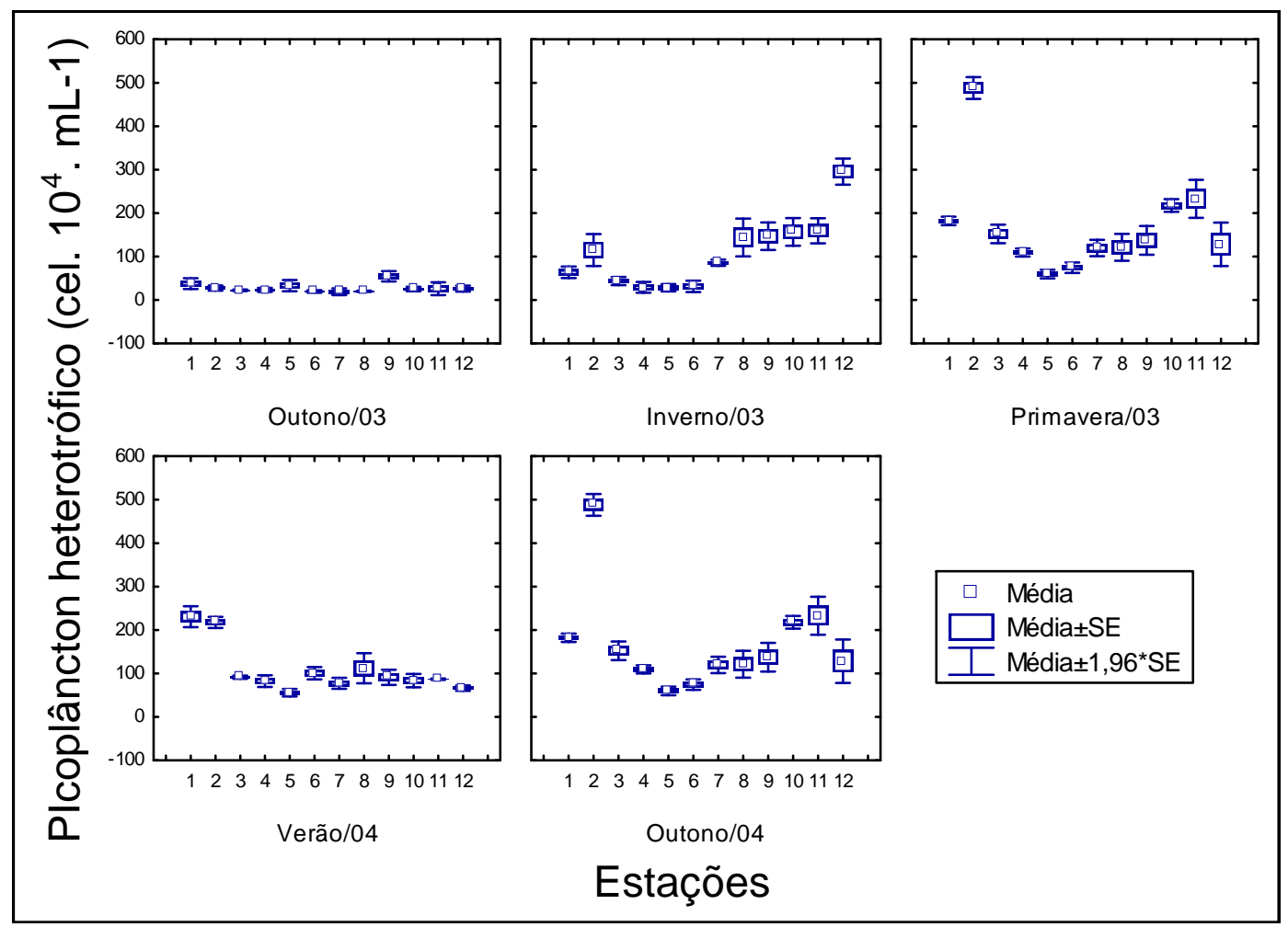

Figura 4 - Variação da densidade média do picoplâncton heterotrófico entre as estações nos períodos dos anos amostrados.

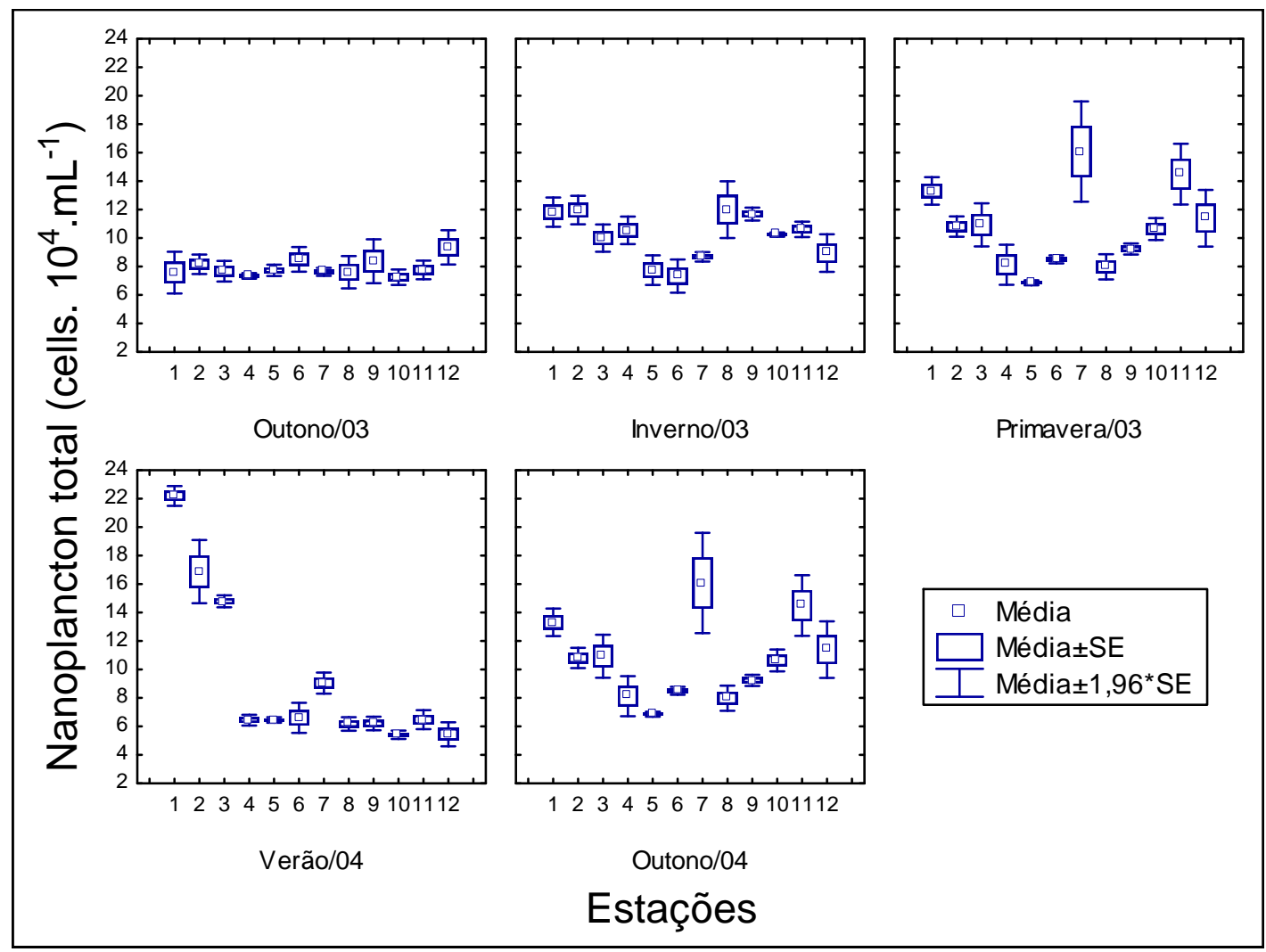

Figura 5 - Variação da densidade média do nanoplâncton total entre as estações nos períodos dos anos amostrados. 
KOLM, H. E.; SIQUEIRA, A. pico, nano e microplâncton em quatro gamboas do município de Pontal do Paraná, Paraná, Brasil.

Como o picoplâncton, o compartimento heterotrófico do nanoplâncton dominou em todas as estações. O nanoplâncton autotrófico (Fig. 6) foi significativamente menor na Gamboa Olho d'Água durante todo o período estudado. Na primavera de 2003 e no outono de 2004 foram observados valores significativamente mais elevados destes organismos nas estações interna (estação 7) e mediana (estação 8) da Gamboa Barranco. Nos demais períodos e estações os valores foram semelhantes.

Assim como para o picoplâncton, no compartimento nanoplancônico, a variação dos organismos heterotróficos também foi semelhante aos totais, com valores mais elevados principalmente na estação 1 (estação interna da Gamboa Perequê) no verão de 2004 (Fig. 7).

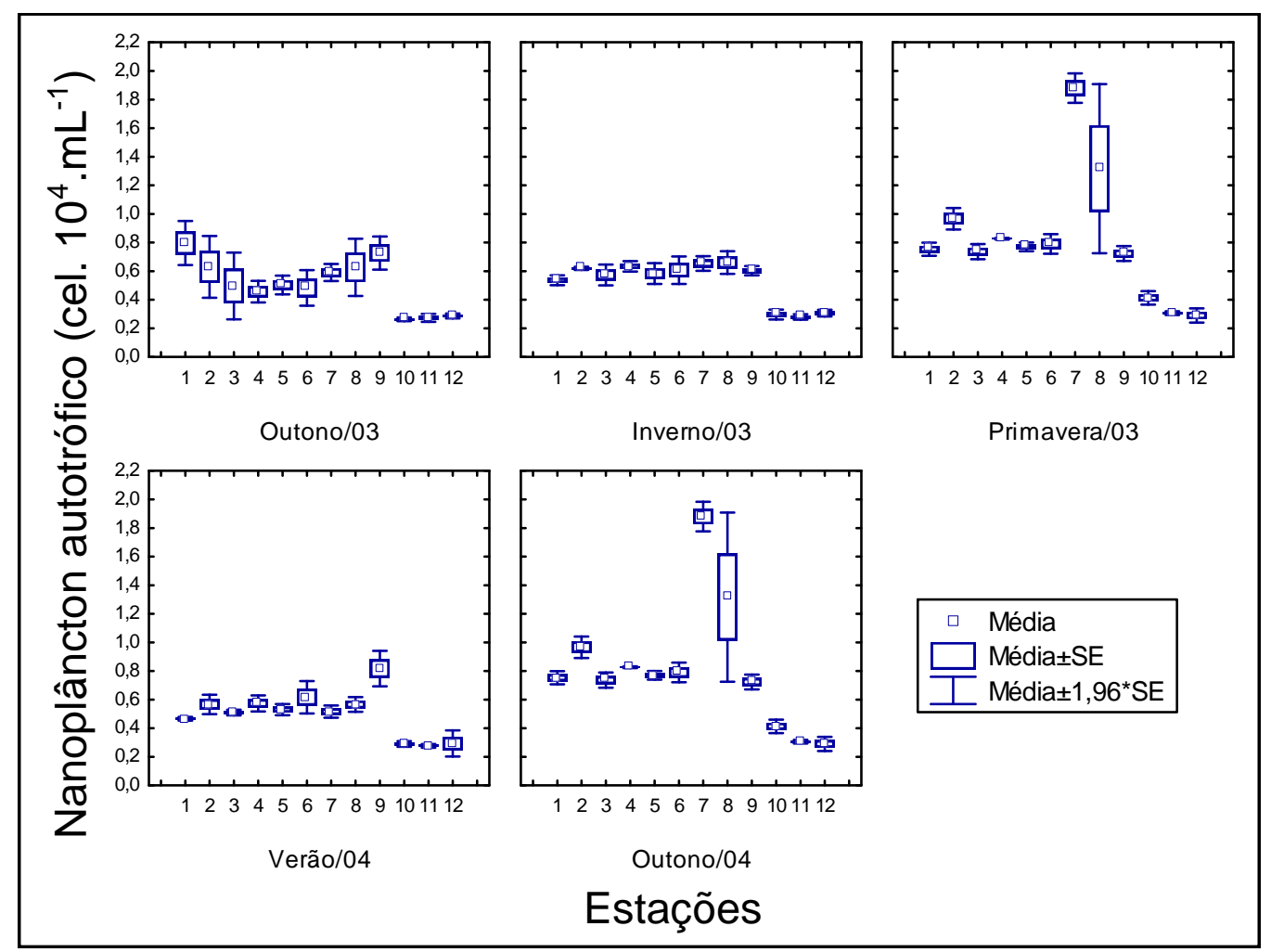

Figura 6 - Variação da densidade média do nanoplâncton autotrófico entre as estações nos períodos dos anos amostrados. 
KOLM, H. E.; SIQUEIRA, A.pico, nano e microplâncton em quatro gamboas do município de Pontal do Paraná, Paraná, Brasil.

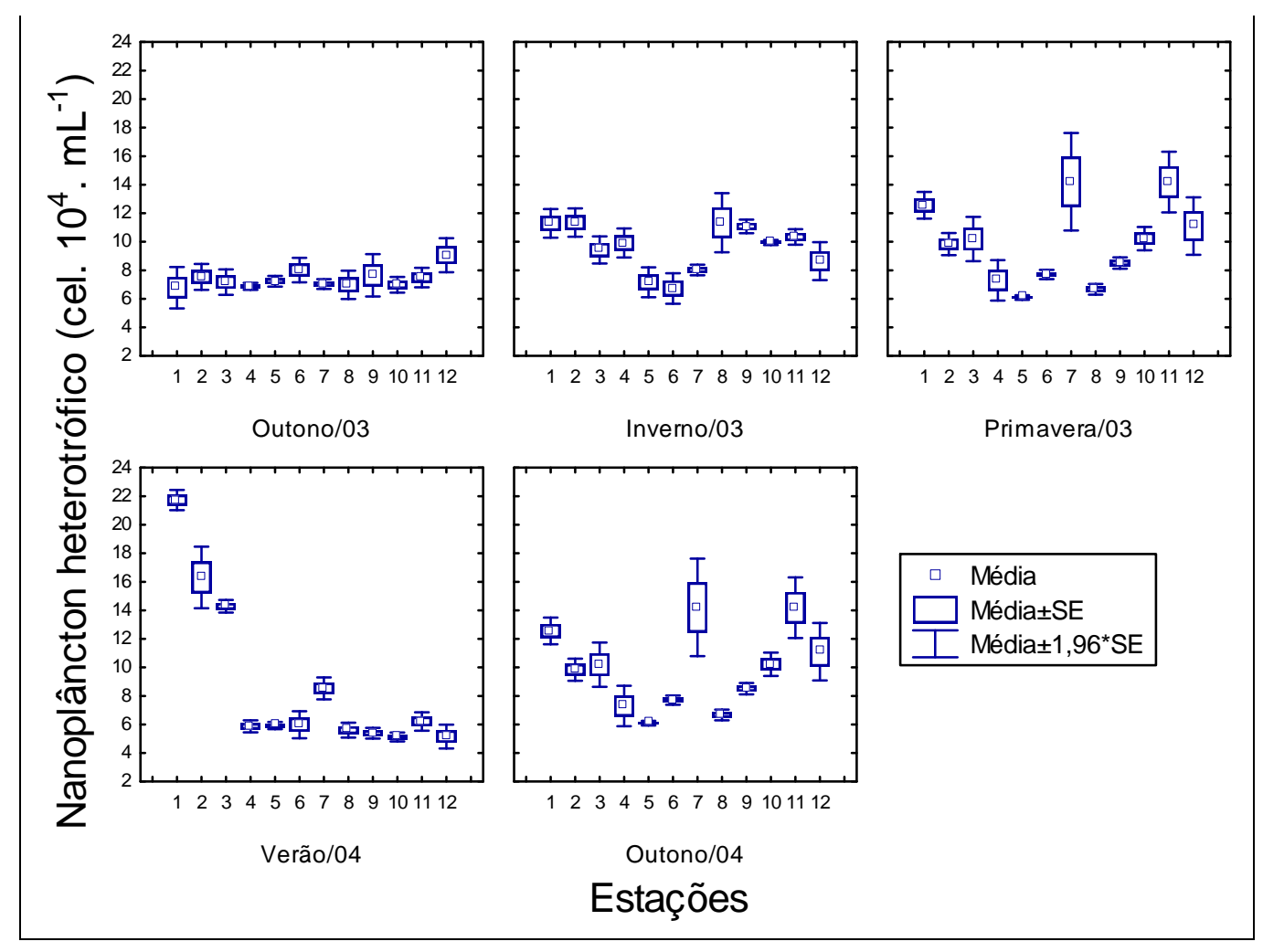

Figura 7 - Variação da densidade média do nanoplâncton heterotrófico entre as estações nos períodos dos anos amostrados.

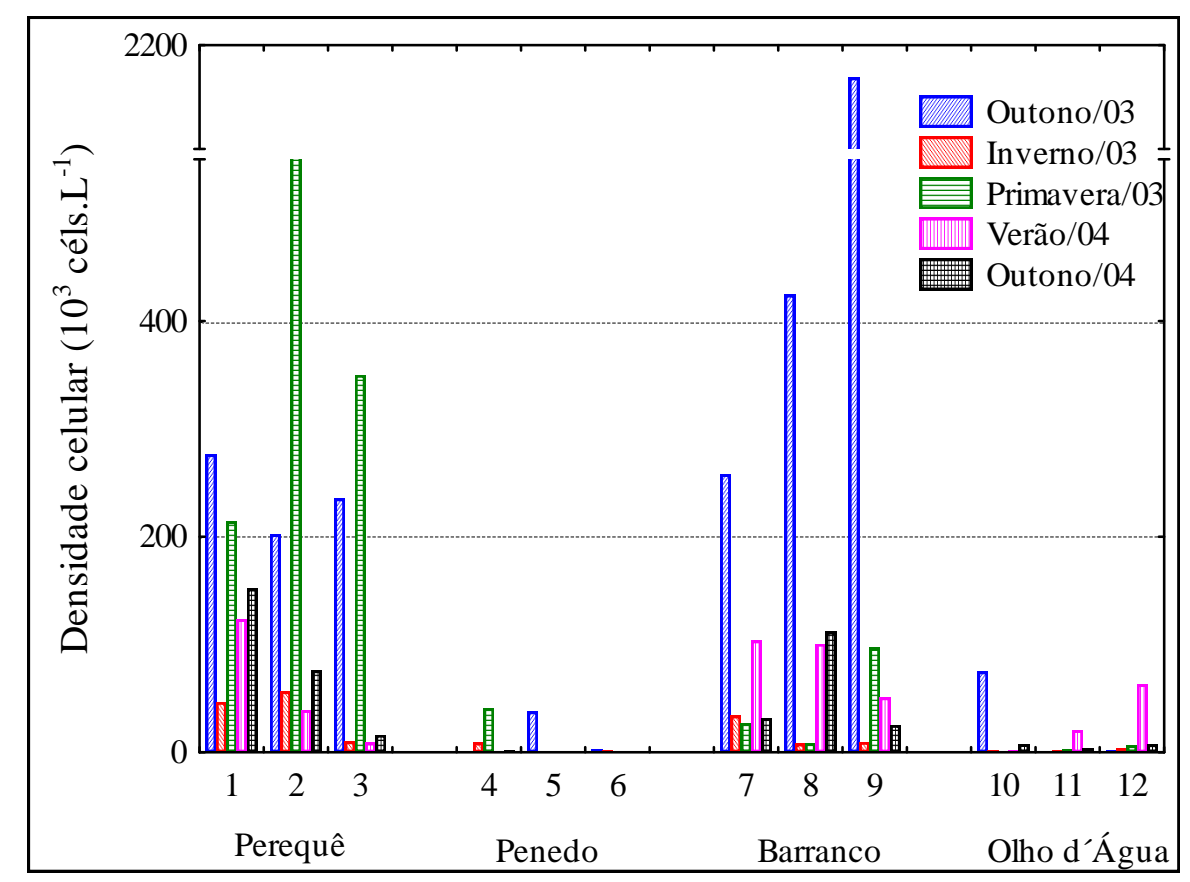

Figura 8. Distribuição espaço-temporal da densidade celular do microplâncton.

A densidade da fração microplanctônica variou de $0,08 \times 10^{3}$ céls. $\mathrm{L}^{-1}$ na estação 5 (Gamboa Penedo) no verão a $1.084 \times 10^{3}$ céls. $L^{-1}$ na estação 9 (Gamboa Barranco) no outono 
KOLM, H. E.; SIQUEIRA, A.pico, nano e microplâncton em quatro gamboas do município de Pontal do Paraná, Paraná, Brasil.

de 2003. De um modo geral, as maiores densidades foram observadas nas gamboas Perequê na primavera e Barranco no outono de 2003 (Fig. 8).

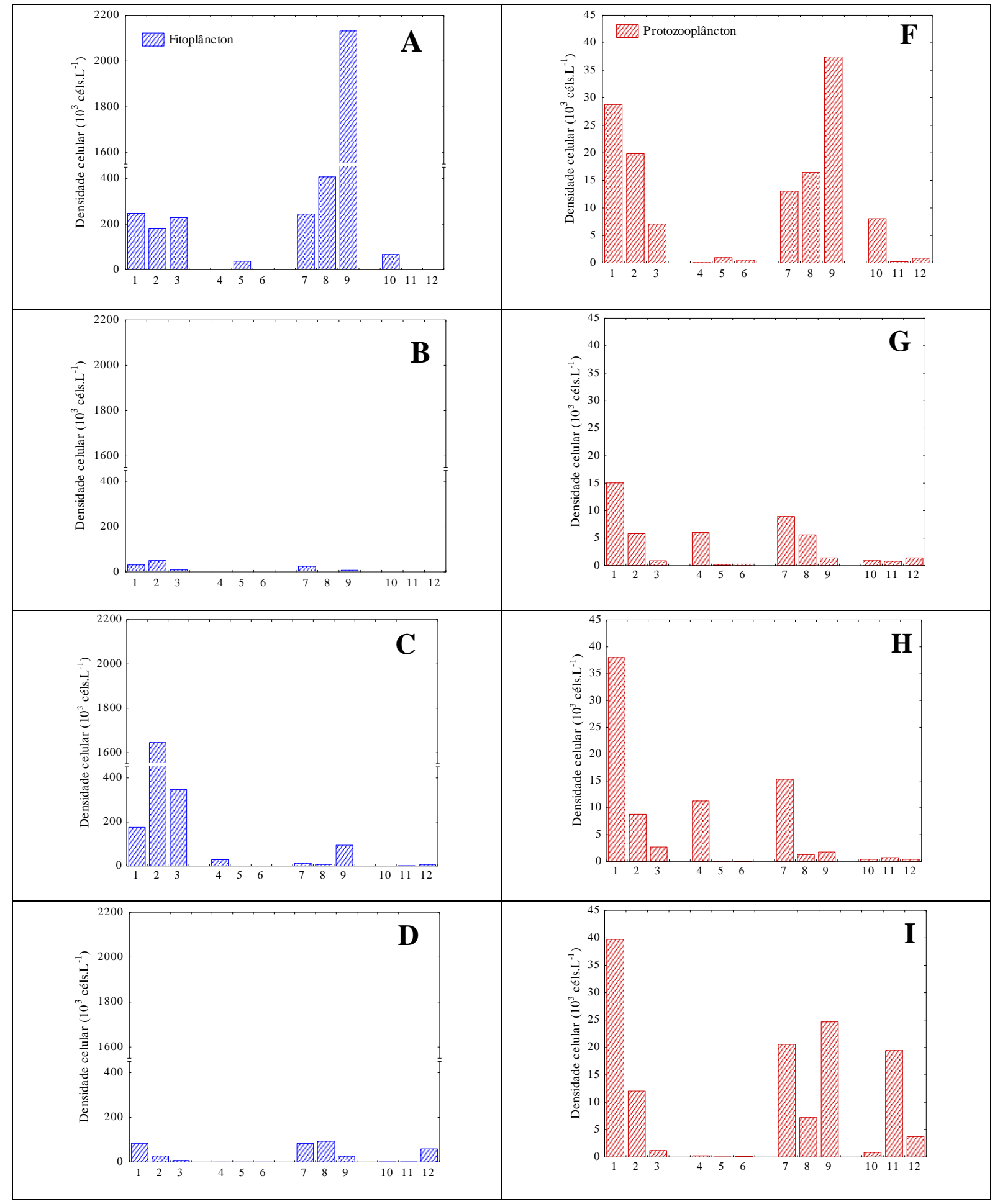


KOLM, H. E.; SIQUEIRA, A.pico, nano e microplâncton em quatro gamboas do município de Pontal do Paraná, Paraná, Brasil.

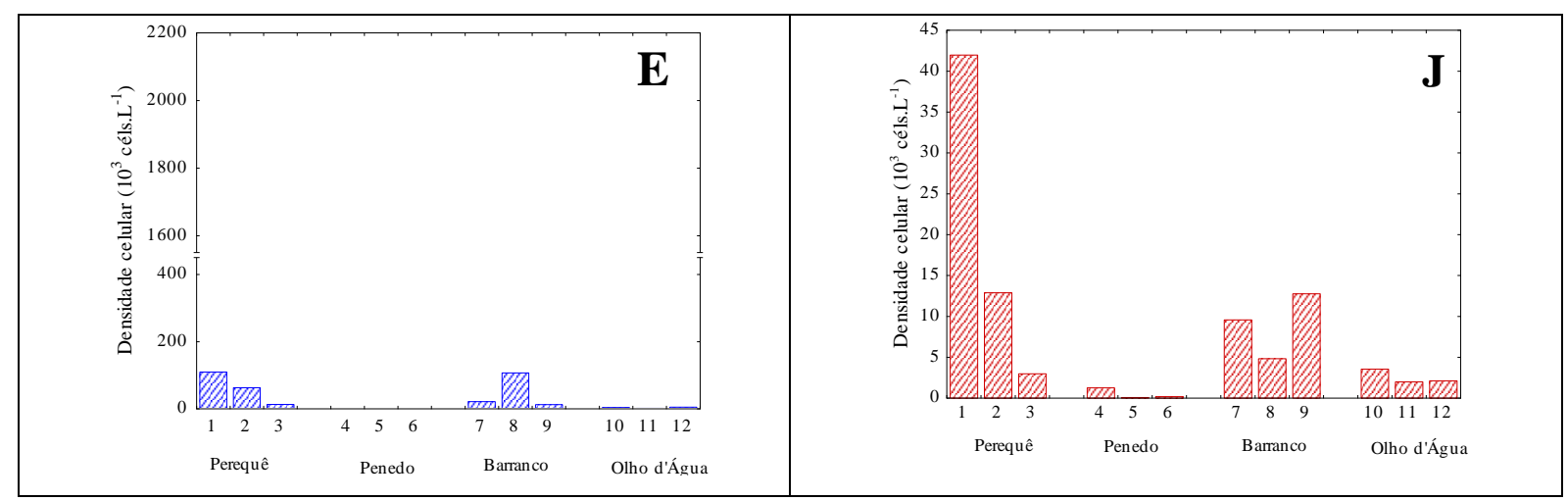

Figura 9 - Contribuição absoluta do fitoplâncton $(A-E)$ e do protozooplâncton ( $F$ - J) em relação à densidade celular (céls. $\mathrm{L}^{-1}$ ): A e F - Outono de 2003; B e G - Inverno de 2003; C e H - Primavera de 2003; D e I - Verão de 2004; E e J - Outono de 2004.

Levando-se em consideração os compartimentos autotróficos e heterotróficos do

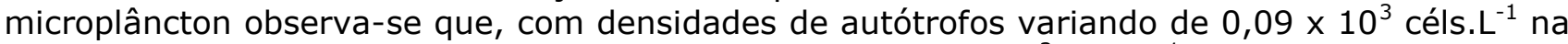
estação 5 (Gamboa Penedo) no inverno de 2003 a 2.131 × $10^{3}$ céls. L $^{-1}$ na estação 9 (Gamboa Barranco), no outono de 2003, houve predominância do fitoplâncton. O protozooplâncton apresentou menores densidades celulares nas três estações da Gamboa Olho d'Água na primavera de 2003 e maior $\left(42 \times 10^{3}\right.$ céls.L $\left.^{-1}\right)$ na estação 1 (Gamboa Perequê) no outono de 2004 (Fig. 9). Assim como observado para o microplâncton total, o fitoplâncton destacou-se principalmente nas gamboas nas gamboas Perequê e Barranco.

Assim como observado para o microplâncton total, o fitoplâncton destacou-se principalmente nas gamboas Perequê e Barranco. Na Gamboa Perequê seus máximos foram observados no outono de 2003 e principalmente na primavera e na Gamboa Barranco no outono de 2003.

O microfitoplâncton, segundo a classificação de Tomas (1997) foi representado pelas Classes Bacillariophyceae (diatomáceas cêntricas e penadas), Cyanophyceae (cianobactérias), Dinophyceae (dinoflagelados), Dictyochophyceae (silicoflagelados) e por várias classes representantes dos flagelados (apenas individualizados, devido à dificuldade de identificação das amostras fixadas).

Dentre as classes observadas destacaram-se, ao longo do período estudado, as diatomáceas penadas com maior representatividade através do gênero Navícula e os dinoflagelados onde se destacou o gênero Gymnodinium. As diatomáceas cêntricas foram registradas com maior frequência nas três estações da Gamboa Penedo. As cianobactérias apareceram de forma mais esporádica nas gamboas durante os meses estudados. Com exceção do outono de 2003, observou-se uma maior frequência dos flagelados na Gamboa Olho d'Água. Os silicoflagelados, representados unicamente pelo gênero Dictyocha, foram os menos frequentes.

No protozooplâncton foram encontrados ciliados aloricados e loricados (tintinídeos), ambos pertencentes à Classe Ciliata, e tecamebas.

Os ciliados aloricados foram os mais frequentes em todas as estações. No outono de 2003 atingiram $100 \%$ na maioria das estações de coleta. Nos demais meses, inclusive no outono de 2004, foram observados ciliados loricados (tintinídeos). Sua maior frequência foi observada na estação externa (Est. 6) da Gamboa Penedo e nas três estações da Gamboa Barranco, ultrapassando os $40 \%$ na estação 9 . As tecamebas representaram o terceiro e último lugar (< $15 \%$ do total). Na análise de ordenação (MDS) as gamboas, com suas respectivas estações, não formaram agrupamentos distintos. Dentro de um único mês as gamboas foram diferentes umas das outras em relação à composição microplâctonica, distribuindo-se de forma heterogênea ao longo dos meses analisados (Fig. 10). 
KOLM, H. E.; SIQUEIRA, A.pico, nano e microplâncton em quatro gamboas do município de Pontal do Paraná, Paraná, Brasil.

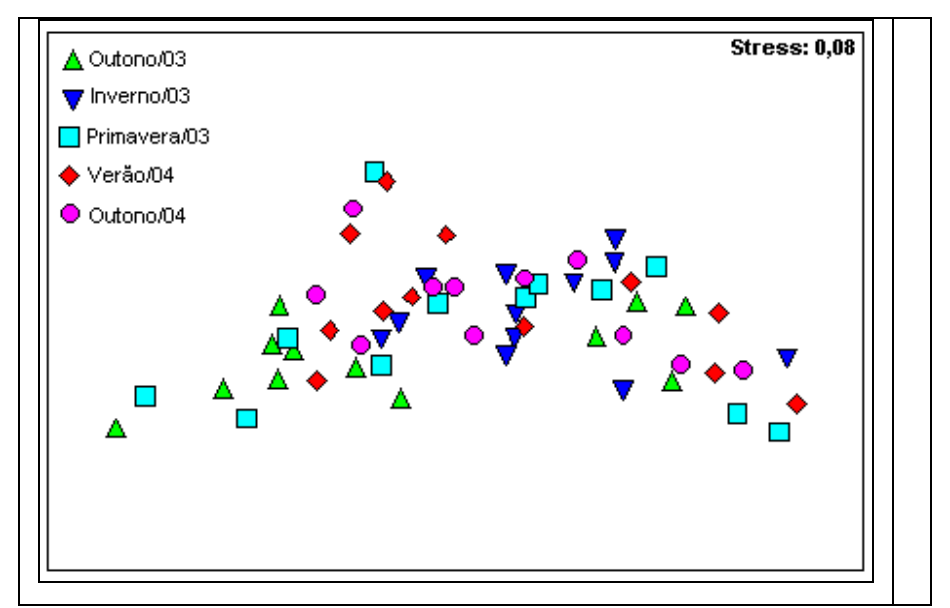

Figura 10 - Ordenamento MDS das estações do ano nas gamboas estudadas em relação aos grupos taxonômicos do microplâncton.

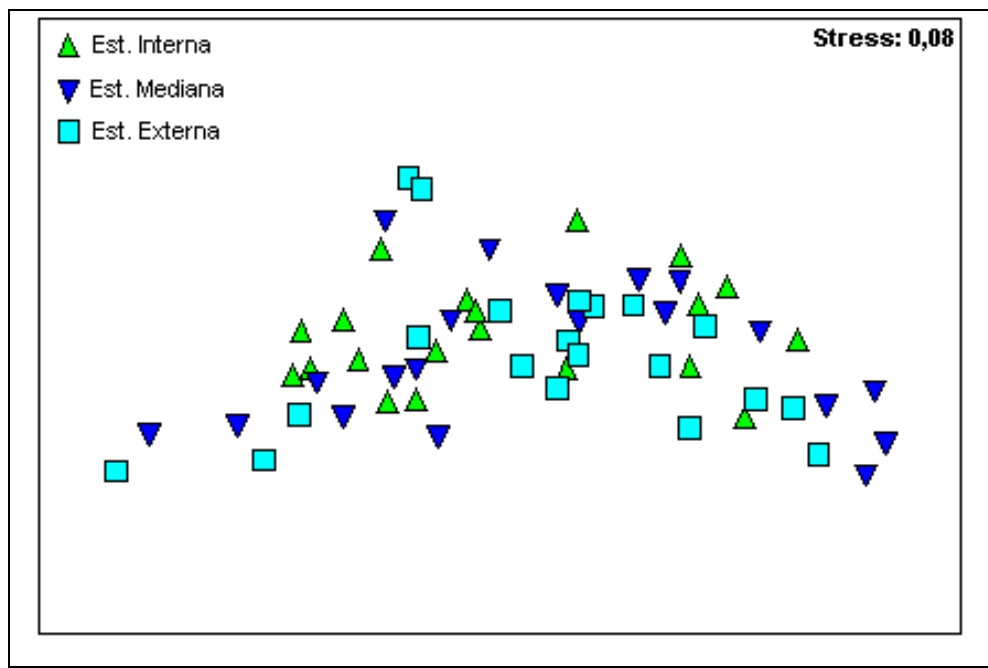

Figura 11 - Ordenamento MDS das estações, nas quatro gamboas ao longo do período estudado em relação aos grupos taxonômicos do microplâncton.

Além disso, também não foi constatado nenhum padrão de ordenamento, com relação aos grupos taxonômicos do microplâncton, entre as estações amostrais interna, mediana e externa (MDS - Fig. 11). O resultado da ANOSIM confirmou a falta de diferenciação entre as estações em relação à densidade dos grupos taxonômicos do microplâncton ( $p>0,05)$.

No diagrama MDS, apoiado pela ANOSIM, é possível observar a existência de um padrão na distribuição das diferentes gamboas segundo a composição dos grupos taxonômicos do microplâncton analisados. As gamboas Perequê e Barranco são muito semelhantes entre si, formando um único grupo (grupo 1). As gamboas Olho d'Água (grupo 2) e Penedo (grupo 3 ) embora apresentem semelhanças, apresentam características distintas (Fig. 12). O resultado do teste da ANOSIM confirmou que as diferenças observadas entre as gamboas analisadas são significativas (Tab. 1). 
KOLM, H. E.; SIQUEIRA, A.pico, nano e microplâncton em quatro gamboas do município de Pontal do Paraná, Paraná, Brasil.

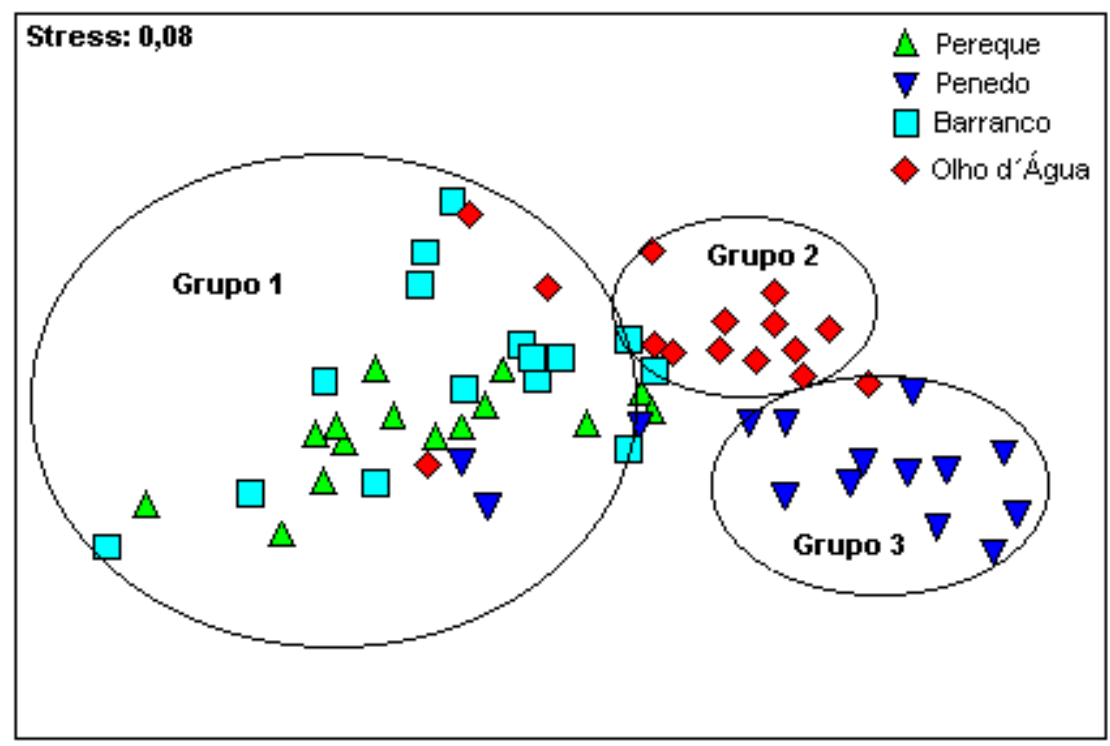

Figura 12 - Ordenamento MDS das gamboas ao longo do período estudado em relação aos grupos taxonômicos do microplâncton.

Tabela 1 - Análise de similaridades ANOSIM para cada uma das gamboas.

\begin{tabular}{c|c|c|c}
\hline \multirow{2}{*}{ R global = 0,431 } & $\mathbf{p = 0 , 1 \%}$ & \multicolumn{2}{|c}{$\mathbf{N}>999$} \\
\cline { 2 - 4 } & $\mathbf{R}$ & $\mathbf{p}$ & $\mathbf{N}$ \\
\hline Perequê - Penedo & 0,681 & 0,1 & $>999$ \\
\hline Perequê - Barranco & 0,047 & 12,1 & $>999$ \\
\hline Perequê - Olho d'Água & 0,584 & 0,1 & $>999$ \\
\hline Penedo - Barranco & 0,584 & 0,1 & $>999$ \\
\hline Penedo - Olho d'Água & 0,330 & 0,1 & $>999$ \\
\hline Barranco - Olho d'Água & 0,356 & 0,1 & \\
\hline
\end{tabular}

Tendo como base a formação dos três grupos de gamboas do diagrama MDS (Fig. 12), a análise de similaridade de percentagens (SIMPER) mostrou que os dinoflagelados foram os organismos mais comuns $(51,55 \%)$ no grupo 1 . No grupo 2 foram os ciliados aloricados $(49,02 \%)$ e no grupo 3 as diatomáceas cêntricas $(37,06 \%)$, seguidas pelas penadas $(30,14 \%)$. Também foi possível observar que a dissimilaridade foi maior entre os grupos 1 e $3(93,69 \%)$, tendo como maior contribuinte os dinoflagelados $(55,02 \%$ da dissimilaridade entre os dois grupos). Entre os grupos 1 e $2(90,28 \%)$ os representantes discriminantes também foram os dinoflagelados, responsáveis por $55,91 \%$ da dissimilaridade entre esses grupos. Os organismos que mais contribuíram para a dissimilaridade existente entre os grupos 2 e $3(82,03 \%)$ foram os ciliados aloricados $(30,12 \%)$ e os dinoflagelados $(28,47 \%)$ (Tab. 2$)$.

Tabela 2 - Contribuição percentual (\%) dos grupos taxonômicos mais abundantes e constantes nas gamboas estudadas, para a similaridade dentro ( $P-1)$ do grupo 1 (Perequê e Barranco), do grupo 2 (Olho d'Água) e do grupo 3 (Penedo) e para a dissimilaridade entre (P-2) esses grupos $(1 \times 2),(1 \times 3)$ e $(2 \times 3)$. (SM): similaridade média; $(D M)$ : dissimilaridade média. $D C=$ Diatomácea cêntrica; $D P=$ Diatomácea 
KOLM, H. E.; SIQUEIRA, A.pico, nano e microplâncton em quatro gamboas do município de Pontal do Paraná, Paraná, Brasil.

penada $; \mathrm{F}=$ Flagelados $;$ Dino $=$ Dinoflagelados $; \mathrm{CA}=$ Ciliados aloricados.

\begin{tabular}{|c|c|c|c|c|c|c|c|}
\hline P-1 & $\begin{array}{c}1 \\
(S M=34,6)\end{array}$ & $\begin{array}{c}2 \\
(S M=31,6)\end{array}$ & $\begin{array}{c}3 \\
(S M=29,1)\end{array}$ & P-2 & $\begin{array}{c}1 \times 2 \\
(D M=90,3)\end{array}$ & $\begin{array}{c}1 \times 3 \\
(D M=93,7)\end{array}$ & $\begin{array}{c}2 \times 3 \\
(D M=82,0)\end{array}$ \\
\hline DDC & 20,4 & & 37,1 & DDC & 5,0 & 4,8 & 5,8 \\
\hline DDP & 20,1 & 12,5 & 30,1 & DDP & 17,3 & 17,4 & 19,3 \\
\hline FF & & 9,9 & & FF & & & 9,4 \\
\hline $\begin{array}{c}\text { DDin } \\
0\end{array}$ & 51,6 & 21,5 & & DDino & 55,9 & 55,0 & 28,5 \\
\hline $\mathbf{C C a}$ & & 49,0 & 22,9 & CCA & 14,6 & 15,6 & 30,1 \\
\hline
\end{tabular}

Tabela 3 - Percentual (\%) médio da densidade dos componentes planctônicos para cada gamboa. G1 = Perequê; G2 = Penedo; G3 = Barrancos e G4 = Olho d'Água.

\begin{tabular}{|l|r|r|r|r|}
\hline \multicolumn{1}{|c|}{ Componentes } & \multicolumn{1}{c|}{ G1 } & \multicolumn{1}{c|}{ G2 } & \multicolumn{1}{c|}{ G3 } & \multicolumn{1}{c|}{ G4 } \\
\hline Picoplâncton Autotrófico & 1,4 & 3,0 & 1,8 & 1,4 \\
\hline Picoplâncton Heterotrófico & 92,0 & 87,5 & 91,4 & 93,5 \\
\hline Nanoplâncton Autotrófico & 0,3 & 0,7 & 0,5 & 0,2 \\
\hline Nanoplâncton Heterotrófico & 4,9 & 6,6 & 4,6 & 3,8 \\
\hline Microfitoplâncton & 0,01 & $<0,01$ & 0,02 & $<0,01$ \\
\hline 'Protozooplâncton & $<0,01$ & $<0,01$ & $<0,01$ & $<0,01$ \\
\hline
\end{tabular}

Na Tab. 3 pode ser observado que em todas as gamboas, as densidades de picoplâncton e nanoplâncton heterotrófico foram maiores que as dos componentes autotróficos. Apesar das pequenas diferenças quantitativas, o picoplâncton heterotrófico foi mais abundante na Gamboa Olho d'Água, seguida de perto pela Gamboa Perequê.

\section{DISCUSSÃO}

O fato da abundância do picoplâncton e nanoplâncton heterotrófico ter sido maior que os componentes autotróficos confirma a hipótese de que o metabolismo dos ambientes investigados é predominantemente heterotrófico.

A classe de tamanho que se destacou quantitativamente na presente pesquisa foi a do picoplâncton heterotrófico, perfazendo em todas as gamboas mais de $85 \%$ do total. Fuhrman et al., (1989) relatam que na zona eufótica do Mar do Sargaço o picoplâncton heterotrófico ultrapassa os $70 \%$ do total dos organismos planctônicos. Estes resultados mostram que tais características não são restritas a ambientes costeiros. Entretanto, há indícios de que, quanto mais próximo da costa estiver o ambiente, maior é a variabilidade quantitativa entre as diferentes classes de tamanho.

Segundo os autores acima, estes micro-organismos ainda são de alta relevância ecológica como consumidores de carbono orgânico dissolvido (COD) proveniente de exudatos celulares e da herbivoria. Apesar de não ter sido feita à análise do COD nesta pesquisa, observações óticas (coloração escura) mostram que as gamboas estudadas contêm grande quantidade de matéria orgânica dissolvida (MOD), proveniente dos manguezais e restingas adjacentes, o que pode ter beneficiado o desenvolvimento desta classe de organismos.

Enquanto a Gamboa Olho d'Água, que parece conter grandes quantidades de MOD devido às suas características de eutrofização e pouca troca de água causada principalmente pela grande quantidade de macrófitas, a Gamboa Perequê é a que possui, dentre as gamboas 
KOLM, H. E.; SIQUEIRA, A. pico, nano e microplâncton em quatro gamboas do município de Pontal do Paraná, Paraná, Brasil.

estudadas, a maior quantidade de manguezais em suas margens (região entre-marés) que são, segundo Twilley $(1985,1988)$, importantes fontes de produção de carbono orgânico. Tais características parecem justificar as grandes quantidades de picoplâncton heterotrófico nestas gamboas. Além disto, pode ser observado que no outono de 2003 as quantidades, tanto de pico quanto de nanoplâncton, foram semelhantes em todas as estações. Neste período foram observados, por Siqueira et al., (2009), valores constantemente baixos de nitrito e fosfato em todas as estações. Segundo Felip; Pace; Cole (1996) e Farjalla et al., (2006) bactérias necessitam além de carbono, nitrogênio e fósforo para o seu crescimento. Como neste período a quantidade de protozooplâncton variou de uma estação e de uma gamboa para outra, os resultados sugerem que houve um controle "botton up" do pico e nanoplâncton heterotrófico.

Autores como Mesquita; Fernandes (1996) registraram, durante o verão, na região costeira de Ubatuba valores para bactérias heterotróficas totais, contadas em microscopia de epifluorescência, entre 1,0 a 2,69 × $10^{6}$ céls. $\mathrm{mL}^{-1}$. Valores próximos a esses (entre 0,5 a 2,3 $\mathrm{x}$ $10^{6}$ céls. $\mathrm{mL}^{-1}$ no verão e 0,6 e $2,9 \times 10^{6}$ céls. $\mathrm{mL}^{-1}$ no inverno) foram registrados para o picoplâncton heterotrófico nesta pesquisa. Da mesma forma Siqueira; Kolm (2005) encontraram, em um estudo feito entre maio de 1998 e maio de 1999, em uma estação na desembocadura da Gamboa do Maciel, localizada na região eualina da Baía de Paranaguá, valores de bactérias heterotróficas totais $\left(0,6\right.$ a 3,5 $\times 10^{6}$ céls. $\left.\mathrm{mL}^{-1}\right)$ semelhantes aos desta pesquisa. Ainda Ribeiro; Kolm; Machado (2011) encontraram, em um estudo feito entre dezembro de 2005 e agosto de 2006, na Zona de Máxima Turbidez, localizada entre Paranaguá e Antonina, valores entre $0,15 \times 10^{6}$ e 2,55 × $10^{6}$ céls. $\mathrm{mL}^{-1}$. Entretanto, Kolm et al., (2002) encontraram valores mais elevados $\left(12,72 \times 10^{6}\right.$ céls. $\left.\mathrm{mL}^{-1}\right)$ em águas superficiais na região interna da Baía de Antonina. Tais resultados mostram que a quantidade destes organismos diminui à medida que a região sofre maior influência das águas pobres em nutrientes, originárias da plataforma continental.

Na primavera de 2003 e outono de 2004 as quantidades de picoplâncton heterotrófico foram significantemente maiores na estação 2 na primavera de 2003 e no outono de 2004, e nas estações 1 e 2 no verão e na estação 12 no inverno de 2003 e as do nanoplâncton heterotrófico no verão. Da mesma forma na estação 1 puderam ser observados os maiores valores de protozooplâncton. Segundo Siqueira et al., (2009) nas três estações desta gamboa (estações 1, 2 e 3 ) foi observada a maior salinidade e consequentemente o maior pH. Além disto, segundo as autoras somente no verão a estação 1 (estação interna) desta gamboa apresentou características de eutrofização o que sugere que houve uma maior troca d'água causada pela influência da maré e a adaptação a ambientes ácidos pode ter beneficiado estes organismos.

Os valores extremamente baixos (entre 1,4 e 3,0\%) do picoplâncton autotrófico encontrados principalmente no verão de 2004, nas gamboas estudadas nesta pesquisa, indicam que pequenos autotróficos estão mais bem adaptados a condições de oligotrofia. Isto pode ser confirmado por estudos realizados por Teixeira; Gaeta (1991) que mostram que o picoplâncton autotrófico contribuiu com 7 e $100 \%$ do total de carbono assimilado pelo fitoplâncton na região oceânica próxima ao Rio Amazonas, com 18 e 40\% na região costeira de Ubatuba (valores intermediários) e com 3 e $28 \%$ na região estuarina de Cananéia (SP).

Pode-se observar ainda que o picoplâncton autotrófico foi igual em todas as estações e todos os períodos do ano. Ao contrário, as quantidades de nanoplâncton e fitoplâncton foram extremamente baixas nas estações 10, 11 e 12 (todas da Gamboa Olho d'Água). Nesta gamboa foram observados, ao longo de todo o período estudado, baixos valores de oxigênio dissolvido, altos de $\mathrm{N}$-amoniacal, coliformes totais e termotolerantes, uma película de óleo sobre a água assim como macrófitas (Siqueira et al., (2009). Tais características levaram os autores a concluir que esta gamboa era altamente eutrofizada durante todo o período estudado, com máximos no verão. A presença destas contribuições antrópicas assim como sombreamento da água pelas macrófitas podem ter influenciado a baixa quantidade destes organismos.

O microfitoplâncton e o protozooplâncton foram comparativamente menos abundantes que os demais. Estas células maiores, devido ao seu tamanho, tendem a afundar mais facilmente e, portanto, necessitam da turbulência para se manterem na zona eufótica. Elas são 
KOLM, H. E.; SIQUEIRA, A.pico, nano e microplâncton em quatro gamboas do município de Pontal do Paraná, Paraná, Brasil.

capazes de crescer e multiplicar-se rapidamente somente quando condições temporárias de concentrações de nutrientes, disponibilidades de luz e de turbulência são alcançadas (Fogg, 1991). Em duas ocasiões deste estudo as condições parecem ter sido favoráveis para o desenvolvimento desta classe de organismos: na estação externa da Gamboa Barranco no outono de 2003 e na estação mediana da Gamboa Perequê na primavera do mesmo ano.

Embora tenha sido baixa a densidade do protozooplâncton em comparação aos demais micro-organismos $(<0,01 \%)$ analisados no presente estudo, os valores encontrados foram frequentemente mais elevados (máximo de $4,2 \times 10^{4}$ céls. $\mathrm{L}^{-1}$ ) do que os registrados em regiões oceânicas oligotróficas por Leakey; Burkill; Sleigh (1996).

A ordenação do MDS mostrou que, com relação ao microplâncton, as Gamboas Perequê e Barranco foram semelhantes, e que as gamboas Penedo e Olho d'Água diferiram destas e entre si. Estes resultados mostram que cada gamboa tem suas peculiaridades.

A maior representatividade das diatomáceas (penadas e cêntricas) foi registrada na Gamboa Penedo. Resultado semelhante foi encontrado por Tenenbaum et al., (2001) na Baía de Guanabara, onde as diatomáceas, típicas de áreas costeiras do mundo inteiro, foram mais abundantes em águas de salinidade mais baixa, rasas e turvas. Lucila; Pomar; Giuffré (1996), também encontraram uma dominância marcante de diatomáceas na costa oeste da Itália, sugerindo que este organismos estão mais adaptados a regiões costeiras.

De acordo com Sherr et al., (1986), os dinoflagelados são mais adaptados a regiões oceânicas (águas oligotróficas). Trabalhos como os de Cupelo (2000) e Tenembaum et al., (2001), realizados na costa central do Brasil, comprovam esta afirmação. Na presente pesquisa os dinoflagelados constituíram fração importante do microfitoplâncton das gamboas estudadas, destacando-se as gamboas Perequê e Barranco no outono de 2003 e Perequê na primavera do mesmo ano. Segundo Siqueira et al., (2009) a Gamboa Perequê apresentou as maiores salinidades durante todo o período estudado e a Gamboa Barranco apresentou salinidades mais elevadas no outono de 2003 e, consequentemente, águas mais claras, o que pode ter beneficiado o desenvolvimento destes organismos, principalmente devido a uma maior penetração de luz.

Na primavera de 2003 foi feita uma dragagem da região externa da Gamboa Barranco (próximo à estação 9), alterando sua topografia de meandrante para retilínea, com o intuito de aumentar sua vazão. Esta alteração não modificou significativamente a maior parte das variáveis estudadas, exceto o desenvolvimento de grandes quantidades de diatomáceas penadas na estação 9. Em conseqüência da dragagem observou-se, nos períodos subseqüentes, uma alteração do perfil de praia fechando na baixa-mar o canal de vazão. A redução temporária do fluxo d'água parece ter influenciado o desenvolvimento dos dinoflagelados e flagelados nas estações 8 e 9 (mediana e externa) observadas no verão e outono de 2004.

Nas demais estações e épocas do ano destacaram-se as diatomáceas cêntricas e penadas, provavelmente beneficiadas pelo refluxo da água doce.

Vale ressaltar que grandes quantidades de flagelados foram registrados no outono de 2004 nas estações mediana e externa da Gamboa Olho d'Água. Nesta região os moradores, com o intuito de aumentar a vazão, retiram, de tempos em tempos, a Pistia stratiotes. Há indícios de que, com esta interferência antrópica aumente a incidência de luz solar na camada superficial da água beneficiando o seu desenvolvimento.

Em estudos realizados no Mar Mediterrâneo, Pérez et al., (2000) observaram valores de protozooplâncton da ordem de grandeza de $10^{3}$ a $10^{4}$ céls. $\mathrm{L}^{-1}$, sendo a comunidade dominada por ciliados aloricados. Resultados semelhantes puderam ser observados na presente pesquisa.

Em todas as gamboas e durante todo o período estudado foi observada predominância dos ciliados aloricados. A importância ecológica desses organismos é bastante expressiva, sendo considerados grandes consumidores de organismos do pico- e nanoplâncton e, por outro lado, componentes relevantes da dieta de copépodos e outros metazoários (STOECKER; GIFFORD; PUTT, 1994), funcionando como elo entre diferentes componentes da cadeia trófica. 
KOLM, H. E.; SIQUEIRA, A.pico, nano e microplâncton em quatro gamboas do município de Pontal do Paraná, Paraná, Brasil.

No conceito original da alça microbiana (AZAM et al., 1983), os nanoflagelados e os ciliados consomem uma grande quantidade de bactérias. Os sucessivos estudos microbiológicos (SHERR; SHERR; FALLON, 1987; SHERR; SHERR; PEDROS-ALIO, 1989; SHERR; SHERR, 1988; GONZALEZ; SHERR; SHERR, 1990; BERNARD; RASSOULZADEGAN, 1990; EPSTEIN; SHIARIS, 1992; JAMES; HALL; BARRETT, 1996; ICHINOTSUKA; UENO; NAKANO, 2006) em ambientes costeiros e marinhos apoiaram este conceito e mostram que a importância dos nanoflagelados utilizando as bactérias como alimento, tende a ser maior do que a dos ciliados (RASSOULZADEGAN; LAVAL-PENTO; SHELDON, 1988). Assim, pode haver uma competição entre nanoflagelados e ciliados pelo alimento bacteriano, mas tal fato ainda é mal compreendido (ICHINOTSUKA; UENO; NAKANO, 2006). Estes autores, em seu trabalho realizado na Baía de Uchiumi, demonstraram que provavelmente os ciliados dominantes (Strombidium e Strobilidium) não eram importantes consumidores de bactérias, mas sim os nanoflagelados.

Nesta pesquisa não pode ser observado um padrão geral de relação trófica entre os organismos de diferentes classes de tamanho. Foram observadas quantidades maiores de organismos protozooplanctônicos diretamente relacionados com o fitoplâncton nas estações externas de todas as gamboas, destacando-se as da Gamboa Perequê. Entretanto, não puderam ser evidenciadas as preferências alimentares destes organismos. No outono e primavera de 2003 e verão de 2004 pode ser observada uma correlação direta do protozooplâncton com o picoplâncton heterotrófico e correlação inversa no inverno de 2003 e outono de 2004; no inverno, verão e outono de 2004 evidenciou-se relação direta, e no outono de 2003, relação inversa destes organismos com o nanoplâncton heterotrófico. Na primavera, a quantidade de nanoplâncton heterotrófico não influenciou quantitativamente 0 protozooplâncton. Estes resultados indicam que, na região estudada, características tais como maior salinidade, maior transparência da água e principalmente maior quantidade de fitoplâncton parecem ser mais importantes que a maior quantidade de pico- e nanoplâncton heterotrófico que Ihes poderiam servir de alimento.

Pequenas quantidades de tecamebas, registradas principalmente nas gamboas Penedo e Olho d'Água, evidenciam suas características eminentemente dulcícolas.

\section{AGRADECIMENTOS}

Os autores agradecem ao Prof. Dr. Marco Fábio Corrêa pela correção do texto em português e auxílio nas análises estatísticas. Agradecem também à Profa. Dra. Theresinha Monteiro Absher pela tradução do resumo para o inglês.

\section{REFERENCIAS}

ANGULO, R. J.; SOARES, C. R; SOUZA, M. C.; MORAES, V. S.; RODERJAN, C. V.; ODRESKI, L. L. R.; KARAM, N. C.; KARAM, K.; BORZONE, C.; FEUERSCHUETTE, R. C. Diagnóstico do Município de Pontal do Paraná, Subsídio para Elaboração do Plano Diretor. Curitiba: Fundação Universidade Federal do Paraná para o Desenvolvimento da Ciência, da Tecnologia e da Cultura. v. I - Diagnástico, 1999. 172 p.

AZAM, F.; FENCHEL, T.; FIELD, J. G.; GRAY, J. S.; MEYER-REIL, L. A.; THINGSTAD, F. The ecological role of water-column microbes in the sea. Mar. Ecol. Prog. Ser., v. 10, p. 257-263, 1983.

BERNARD, C.; RASSOULZADEGAN, F. Bacteria or microflagellates as a major food source for marine ciliates: possible implications for the microzooplankton. Mar. Ecol. Prog. Ser., v. 64, p. 147-155, 1990.

BRANDINI, F. P.; LOPES, R. M.; GUTSEIT, K. S.; SPACH, H. L.; SASSI, R. Planctonologia na plataforma continental do Brasil: diagnose e revisão bibliográfica. MMA, CIRM, FEMAR, 1997. 196p.

CHRZANOWSKI, T. H.; SPURRIER, J. D. Exchange of microbial biomass between a Spartina alterniflora marsh and the adjacent tidal creek. Estuaries, v. 10, n. 2, p. 118-125, 1987. 
KOLM, H. E.; SIQUEIRA, A.pico, nano e microplâncton em quatro gamboas do município de Pontal do Paraná, Paraná, Brasil.

CRACKNELL, A. P.; NEWCOMBE, S. K.; BLACK A. F.; KIRBY, N. E. The ABDMAP (Algal Bloom Detection, Monitoring and Prediction) concerted action. Int. J. Remote Sens., v. 22, n. 2 \& 3 , p. 205-247, 2001.

CUPELO, A. C. G. As frações do pico-, nano- e microplâncton na profundidade do máximo de clorofila na costa central do Brasil $\left(13,5^{\circ}-2^{\circ} \mathrm{S}\right)$. São Paulo, 2000. Dissertação (Oceanografia Biológica) - Instituto Oceanográfico, Universidades de São Paulo.

EPSTEIN, S. S.; SHIARIS, M. P. Size-selective grazing of coastal bacterioplankton by natural assemblages of pigmented flagellates, colorless flagellates, and ciliates. Microbial Ecol., v. 23, p. 211-225, 1992.

FARJALLA, V.F.; ENRICH-PRAST, A.; ESTEVES, F.A.; CIMBLERIS, A. C. P. Bacterial growth and DOC consumption in a tropical coastal lagoon. Braz. J. Biol., v. 66, n. 2A, p. 383-392, 2006.

FELIP, M.; PACE, M.L; COLE, J.J. Regulation of planktonic bacterial growth rates: The effects of temperature and resources. Microb. Ecol., v. 31, p.15-28, 1996.

FOGG, G. E. The phytoplanktonic ways of life. New Phytol., v. 118, n. 2, p. 191-232, 1991.

FURHMAN, J. A.; SLEETER, T. D.; CARLSON, C. A.; PROCTOR, L. M. Dominance of bacterial biomass in the Sargasso Sea and its ecological implications. Mar. Ecol. Prog. Ser., v. 57, p. 207-217, 1989.

GONZALEZ, J. M.; SHERR, E. B.; SHERR, B. F. Size-selective grazing on bacteria by natural assemblages of estuarine flagellates and ciliates. Appl. Environ. Microb., v. 56, p. 583-589, 1990.

HASLE, G. R. Using the inverted microscope. In: SOURNIA, A. Phytoplankton Manual. Monogr. Oceano. Methodol., v. 6, p. 191-196, 1978.

IBGE. Instituto Brasileiro de Geografia e Estatística. 2012.

http://www.ibge.gov.br/cidadesat/topwindow.htm?1. Acesso em 22.01.2013.

ICHINOTSUKA D.; UENO, H.; NAKANO, S. Relative importance of nanoflagellates and ciliates as consumers of bacteria in a coastal sea area dominated by oligotrichous Strombidium and Strobilidium. Aquat. Microb. Ecol., v. 42, n. 2, p. 139-147, 2006.

JAMES, M. R.; HALL, J. A.; BARRETT, D. P. Grazing by protozoa in marine coastal and oceanic ecosystems off New Zealand. Mar. Freshwater Res., v. 30, p. 313-324, 1996.

KOLM, H. E.; SCHOENENBERGER, M. F. B.; PIEMONT, M. R.; SOUZA, P. S. A.; SCHNELL, E.; SCÜHL, G.; MUCCIATTO, M. B.; MAZZUCO, R. Temporal variation of bacteria in superficial waters of Paranaguá and Antonina Bays, Paraná, Brazil. Braz. Arch. Biol. Techn., v. 45, n. 1, p. 27-34, 2002.

LANA, P. C.; ALMEIDA, M. V. O.; FREITAS, C. A. F.; COUTO, E. C. G.; CONTI, L. M. P.; GONZALEZ-PERONTI, A. L.; GILleS, A. G.; LOPES, M. J. S.; SILVA, M. H. C.; PEDROSO, L. A. Estrutura espacial de estruturas macrobênticas sublitorais da Gamboa Perequê (Pontal do Sul, Paraná.). Nerítica, v. 4, n. 1/2, p. 119-136, 1989.

LEAKEY, R. J. G.; BURKILL, P. H.; and SLEIGH, M. A. Planktonic ciliates in the northwestern Indian Ocean: their abundance and biomass in waters of contrasting productivity, J. Plankton Res., v. 18, p. 1063-1071, 1996.

LUCILA, M.; POMAR, C. A.; GIUFFRÉ, G. Pico-, nano-, and microplankton communities in hydrothermal marine costal environments of the Eolian Islands (Panarea and Vulcano) in the Mediterranean Sea. J. Plankton Res., v. 18, n. 5, p. 715-730, 1996.

MESQUITA, H DE S. L.; FERNANDES, A. J. Variação de curta escala de bactérias, picofitoplâncton e nanoheterótrofos na região de Ubatuba - SP, Brasil. Rev. Bras. Oceanogr. v. 44 (1): 47-56, 1996. 
KOLM, H. E.; SIQUEIRA, A.pico, nano e microplâncton em quatro gamboas do município de Pontal do Paraná, Paraná, Brasil.

PARSONS, T. R.; MAITA, Y.; LALLI, C. M. Direct Counting of Bacteria by Fluorescence Microscopy. A Manual of Chemical and Biological Methods for Seawater Analysis. Pergamon Press, 1984. 173p.

PEREZ M. T.; DOLAN J. R.; VIDUSSI F.; FUKAI E. Diel vertical distribution of planktonic ciliates within the surface layer of the NW Mediterranean (May 1995). Deep-Sea Res. v. 47: p. 479$503,2000$.

RASSOULZADEGAN, F.; LAVAL-PENTO, M.; SHELDON, R. W. Partitioning of the food ration of marine ciliates between pico and nanoplankton. Hydrobiologia, v. 159, p. 75-88, 1988.

RELATÓRIO REVIZEE - Planctonologia na plataforma continental do Brasil: diagnose e revisão bibliográfica. 254p. Disponível na internet

http://www.mma.gov.br/estruturas/revizee/ arquivos/plancto.pdf. Acesso em 15.06.2012.

RIBEIRO, C. G.; KOLM, H. E.; MACHADO, E. da C. Short-Term Variability of Bacterioplankton in the Maximum Turbidez Zone in the Paranaguá Bay, Southern Brazil, and its Relationship with Environmental Variables. Braz. Arch. Biol. Technol. v. 54, n. 5, p. 947-956. 2011.

SHERR, E. B.; SHERR, B. F.; FALLON, R. D.; NEWELL, S. Y. Small, aloricate ciliates as a major component of the marine heterotrophic nanoplankton. Limnol. Oceanogr., v. 31, n. 1, p. 177$183,1986$.

SHERR, B. F.; SHERR, E. B.; FALLON, R. D. Use of monodispersed, fluorescently labelled bacteria to estimate in situ protozoan bacterivory. Appl. Environ. Microb., v. 53, p. 958-965, 1987.

SHERR, E. B.; SHERR, B. F. Role of microbes in pelagic food webs: a revised concept. Limnol. Oceanogr., v. 33, p. 1225-1227, 1988.

SHERR, B. F.; SHERR, E. B.; PEDROS-ALIO, C. Simultaneous measurement of bacterioplankton production and protozoan bacterivory in estuarine water. Mar. Ecol. Prog. Ser., v. 54, p. 209219, 1989.

SIEBURTH, J. M. C. N.; SMETACEK, V.; LENZ, J. Pelagic ecosystem structure: Heterotrophic compartments of plankton and their relationship to plankton size fractions. Limnol. Oceanogr., v. 23, p. 1256-1263, 1978.

SIQUEIRA, A.; KOLM, H. E. Bacterioplâncton na desembocadura da Gamboa do Maciel, Baía de Paranaguá, Paraná, Brasil. Health Environ. J., v. 6, n. 1, p. 20-28, 2005.

SIQUEIRA, A.; GODINHO, M. J. L.; KOLM, H. E.; MACHADO, E. da C. Evaluation of the Water Quality of Tidal Creeks of Pontal do Paraná, Paraná, Brazil. Braz. Arch. Biol. Technol., v. 52, n. 2, p. 483-492, 2009.

STOECKER, D. K.; GIFFORD, D. J.; PUTT, M. Preservation of marine planktonic ciliates: losses and cell shrinkage during fixation. Mar. Ecol. Prog. Ser., v. 110, p. 293-299, 1994.

TEIXEIRA, C.; GAETA, S. A. Contribution of picoplankton to primary production in estuarine, coastal and equatorial waters of Brazil. Hydrobiologia, v. 209, p. 117-122, 1991.

TENENBAUM, D. R.; VILLAC, M. C.; GOMES, E. A. T.; CUPELO, A. C.; SANTOS, V. S. A new "sight" on microbial plankton ecology: Coastal x Oceanic System in Brazil. p. 133-152. In: FARIA, B.M., FARJALLA,V. F.; ESTEVES, F. A. (Eds). Aquat. Microb. Ecol. in Brazil. Rio de Janeiro: Series Oecologia Brasiliensis, vol. IX. PPGE-UFRJ, Rio de Janeiro, 2001. p. 133-152.

TOMAS, C. R. Identifying marine diatoms and dinoflagellates. Academic Press Inc. San Diego, 1997. 858p.

TWILLEY, R. R. The exchange of organic carbon in basin mangrove forest in a south west Florida estuarys. Estuar. Coast. Shelf S., v. 20. p. 543-557. 1985.

TWILLEY, R. R. Coupling of Mangroves to the Productivity of Estuarine and Coastal Waters. In: Coastal offshore Ecosystem Interactions, Jansson B.O. (Ed.). Springer-Verlag, Berlin, 1988. p. 155-180. 
KOLM, H. E.; SIQUEIRA, A. pico, nano e microplâncton em quatro gamboas do município de Pontal do Paraná, Paraná, Brasil.

UTERMÖHL, H. Zur Vervollkomnnung der quantitativen phytoplankton methodik. Mitteilungen - Internationale Vereinigung für Theoretische und Angewandte Limnologie, v. 9, p. 138. 1958.

VALIELA, I. Marine Ecological Processes. 2. ed. Springer-Verlag New York, 1995. 686p.

YONEDA, N. T. Avaliação e ações prioritárias para a conservação da biodiversidade da zona costeira e marinha - Plâncton. Disponível na internet <http://www.bdt.org.br/workshop/costa/plancton/index>. Acesso em: outubro de 2004.

YOUNG, M.; GONNEEA, M. E.; HERRERA-SILVEIRA, J.; PAYTAN, A. Export of dissolved and particulate carbon and nitrogen from a mangrove-dominated lagoon, Yucatan Peninsula, Mexico. Intern. J. Ecol. Environ. Sci., v. 31, n. 3, p. 189-202, 2005. 